\title{
Comunicação
}

[Communication $]$

\section{Prevalência de hipocalcemia e hipomagnesemia em equinos com distúrbios gastrintestinais}

[Prevalence of hypocalcemia and hypomagnesemia in equines with gastrointestinal diseases]

\author{
C.S. Coelho, L.A. Fonseca, V.R.C. Souza
}

Universidade Vila Velha (UVV) - Vila Velha, ES

\begin{abstract}
A hipocalcemia e a hipomagnesemia são achados comuns em humanos com sépsis ou grave trauma (Zaloga et al., 1987) e em cães doentes, nos quais as duas alterações foram associadas à elevada taxa de morbidade e mortalidade (Martin et al., 1994).
\end{abstract}

Em equinos, Dart et al. (1992) e Delesalle et al. (2005) relataram que os animais com doença gastrintestinal que são submetidos à laparotomia exploratória estão em maior risco de desenvolver deficiência de cálcio e magnésio devido a fatores como consumo inadequado, administração intravenosa de fluidos pobres em cálcio e magnésio, ressecção intestinal, íleo adinâmico e sépsis. Ao mesmo tempo, a hipocalcemia e a hipomagnesemia podem contribuir para a piora do quadro de íleo adinâmico devido a sua importante participação na contração da musculatura lisa.

Dart et al. (1992) avaliaram as concentrações de cálcio ionizado em equinos admitidos com cólica abdominal aguda submetidos a tratamento cirúrgico. Todos os 147 animais incluídos apresentaram baixa concentração de cálcio, antes e após o procedimento cirúrgico, sendo as menores concentrações observadas nos equinos com infartos quando comparado com os de obstruções. Garcia-Lopez et al. (2001) relataram que a hipomagnesemia e a hipocalcemia foram achados comuns durante o período perioperatório em equinos submetidos a cirurgias devido a diferentes lesões gastrintestinais. Segundo esses autores, $57 \%$ e $17 \%$ dos equinos apresentaram baixas concentrações séricas, respectivamente, de cálcio total e magnésio total. Destacam, nesse experimento, que a avaliação

Recebido em 10 de março de 2011

Aceito em 21 de março de 2012

E-mail: clarisse.coelho@uvv.br das formas ionizáveis foi mais sensível na detecção de suas deficiências quando comparado com avaliação das formas totais.

Ao avaliarem a prevalência de hipomagnesemia e hipocalcemia em equinos, Delesalle et al. (2005) observaram que $88 \%$ dos 144 equinos admitidos com dor abdominal aguda apresentaram hipocalcemia, e estes animais apresentavam pior prognóstico devido à maior probabilidade de desenvolverem íleo adinâmico durante a hospitalização, semelhante ao supracitado por outros autores. Também, Navarro et al. (2005), ao estudarem os desequilíbrios eletrolíticos e ácido-base em 115 equinos com distúrbios gastrintestinais distribuídos em quatro categorias - obstruções, isquemias, inflamações e problemas diarreicos , encontraram hipocalcemia em todos os equinos com cólica.

Johansson et al. (2003) verificaram associação de hipomagnesemia com alterações como cólica, diarreia aguda e outras doenças gastrintestinais, sendo que a hipomagnesemia foi associada aos períodos maiores de internação. $\mathrm{O}$ reconhecimento e a correção precoces das deficiências de cálcio e de magnésio podem ajudar a reduzir a mortalidade e a morbidade em equinos com cólica relacionadas, principalmente, com complicações como o íleo adinâmico. Segundo Delesalle et al. (2005), a reposição de cálcio, conforme também recomendou GarciaLopez et al. (2001), aumentou a probabilidade de sobrevivência.

Devido à escassez de informações na literatura nacional e à importância do tema para a clínica de equinos, o objetivo do presente trabalho foi 
estabelecer a prevalência da hipocalcemia e da hipomagnesemia em equinos com cólica de origem gastrintestinal atendidos no Hospital Veterinário da Faculdade de Medicina Veterinária e Zootecnia da Universidade Vila Velha-ES.

Foram revisados os dados de 12 equinos adultos - com mais de um ano de idade -, encaminhados para atendimento ao Setor de Grandes Animais do Hospital Veterinário Alexandre Hippler da Universidade Vila Velha (UVV), Vila Velha, ES, por apresentarem lesões de origem no trato gastrintestinal entre março e dezembro de 2009. Registraram-se as informações relacionadas com raça, idade, sexo, diagnóstico estabelecido por meio de exame clínico, tipo de terapia estabelecida - medicamentosa ou cirúrgica - e evolução do quadro. Os animais que receberam cálcio durante a terapia antes de chegarem ao hospital foram descartados.

As amostras de sangue foram obtidas no momento da chegada e com um, três, cinco e sete dias após a admissão, posteriormente à antissepsia local, por meio de venopunção da jugular com agulhas descartáveis, utilizando-se sistema a vácuo (Vacutainer), em tubos de vidro contendo anticoagulante EDTA K3, para avaliação do micro-hematócrito e em tubos de vidro siliconizados sem anticoagulantes, para as determinações séricas de proteína total (Strufaldi, 1987), cálcio total (Sarkar e Chauhan, 1967) e magnésio total (Mann e Yoe, 1957).

A análise dos resultados foi feita usando-se testes paramétricos - análise de variância e comparação entre médias pelo teste $\mathrm{t}$ com nível de significância a $5 \%$-, utilizando-se programa computadorizado GraphInstat versão 3.00, para as diferentes variáveis - hematócrito, proteína total, cálcio e magnésio totais.

Foram nove machos $(75 \%)$ e três fêmeas $(25 \%)$, com média de idade de 5,5 anos, das raças
Mangalarga Marchador $(n=6)$, Árabe $(n=1)$, Quarto de Milha $(n=1)$ e mestiços $(n=4)$. Dentre os equinos incluídos, um apresentava lesão no estômago (sobrecarga gástrica), três no intestino delgado (uma compactação de íleo e duas hérnias inguino-escrotal encarceradas) e sete no intestino grosso (quatro compactações de cólon maior, dois deslocamentos de cólon maior e uma compactação de cólon transverso). Um equino foi sacrificado durante o procedimento cirúrgico em razão de ruptura do ceco. A terapia medicamentosa foi instituída em três casos, sendo duas compactações de cólon maior e uma sobrecarga gástrica, com resultados satisfatórios em $100 \%$ dos casos. Oito equinos foram submetidos à terapia cirúrgica para realização de procedimentos, tais como evacuação de material compactado em intestino grosso e enterectomia seguida de enterotomia de intestino delgado, com índice de sobrevivência de $50 \%$.

$\mathrm{Na}$ avaliação do hematócrito e das proteínas plasmáticas totais, não houve diferenças significativas entre os momentos de coleta. Isso conota que a desidratação apresentada nos casos atendidos não foi considerada grave.

$\mathrm{Na}$ avaliação do cálcio sérico, não houve diferença estatística significante entre os momentos da coleta $(\mathrm{P}>0,05)$, e isso se repetiu na avaliação do magnésio sérico (Tab. 1). No grupo experimental, em todos os momentos os valores de referência registrados foram mais baixos que os de Rose e Hodgson (2000), para ambas as variáveis. Tal fato corrobora com as informações de Dart et al. (1992), Garcia-Lopez et al. (2001) e Navarro et al. (2005), que ressaltaram a ocorrência relativamente comum de hipocalcemia durante o período de internação e pós-operatório por causas multifatoriais, tais como ressecção intestinal, falha da suplementação, íleo adinâmico, sépsis e endotoxemia.

Tabela 1. Valores médios (x) e desvios-padrão (s) do volume globular (VG), proteína total, cálcio e magnésio séricos em equinos com distúrbios gastrintestinais, nos momentos pré (T0) e com 1 (T1), 3 (T3), 5 (T5) e 7 (T7) dias após a admissão em Hospital Escola

\begin{tabular}{lccccc}
\hline & T0 $(\mathrm{n}=11)$ & $\mathrm{T} 1(\mathrm{n}=9)$ & $\mathrm{T} 3(\mathrm{n}=7)$ & $\mathrm{T} 5(\mathrm{n}=6)$ & $\mathrm{T} 7(\mathrm{n}=5)$ \\
\hline VG $(\%)$ & $31,0 \pm 2,3$ & $35,3 \pm 8,8$ & $32,0 \pm 10,9$ & $32,6 \pm 7,2$ & $33,5 \pm 7,5$ \\
Proteína total (g/dL) & $6,1 \pm 1,2$ & $6,3 \pm 1,5$ & $6,6 \pm 1,7$ & $6,3 \pm 1,1$ & $6,4 \pm 0,7$ \\
Cálcio $(\mathrm{mg} / \mathrm{dL})$ & $9,3 \pm 1,3$ & $8,6 \pm 1,2$ & $9,6 \pm 1,6$ & $10,1 \pm 1,1$ & $9,6 \pm 0,8$ \\
Magnésio $(\mathrm{mg} / \mathrm{dL})$ & $1,4 \pm 0,2$ & $1,4 \pm 0,4$ & $1,7 \pm 0,5$ & $1,5 \pm 0,2$ & $1,6 \pm 0,8$ \\
\hline
\end{tabular}

Não houve diferença entre tempos para todas as características avaliadas. 
$\mathrm{Na}$ avaliação do magnésio sérico, os valores foram similares aos descritos por Garcia-Lopez et al. (2001), destacando-se o maior comprometimento do magnésio sérico nos quadros de lesões gastrintestinais. Semelhantemente, Costa et al. (2001) e Johansson et al. (2003) relataram prevalência de, respectivamente, $42 \%$ e $48,7 \%$ de equinos hospitalizados com hipomagnesemia. Costa et al. (2001) ainda destacaram que a deficiência de magnésio em equinos com doenças no trato gastrintestinal é a anormalidade eletrolítica mais comum.

Foi feita, adicionalmente, uma comparação dos valores do cálcio sérico total no grupo de animais sobreviventes e não sobreviventes no dia da admissão ao Hospital Veterinário (T0). No grupo dos sobreviventes, o valor médio do cálcio sérico no dia da admissão foi de $10,1 \pm 0,8 \mathrm{mg} / \mathrm{dL}$, maior $(\mathrm{p}=0,0072)$ do que o valor observado no grupo dos não sobreviventes $(8,4 \pm 1,3 \mathrm{mg} / \mathrm{dL})$, o que conota maior déficit de cálcio nestes animais em decorrência, provavelmente, de um estado mais grave. Delesalle et al. (2005) também constataram hipocalcemia no dia de admissão ao hospital em $88 \%$ dos equinos avaliados e correlacionaram a mortalidade com valores bem baixos de cálcio sanguíneo. Os resultados sugerem a possibilidade do uso do valor de cálcio sérico como índice prognóstico. Este mesmo achado não foi repetido para o magnésio sérico, semelhantemente ao descrito por Johansson et al. (2003), que não estabeleceram uma correlação entre hipomagnesemia e mortalidade.

Segundo Garcia-López et al. (2001), a determinação de cálcio e magnésio totais, como feito no presente estudo, seria menos sensível na avaliação da hipocalcemia e hipomagnesemia do que a determinação das formas ionizáveis, e isto é atribuído a alterações nas concentrações séricas de proteínas, que não oscilaram na presente pesquisa, conforme citado, e ao quadro de acidose metabólica, não mensurado. Porém, a determinação das formas totais de cálcio e magnésio foi feita porque ainda se mostra mais acessível e de baixo custo, devendo os resultados sempre ser associados ao quadro clínico do animal. Devem-se mensurar tanto as formas totais quanto as ionizadas de cálcio e magnésio, visando estabelecer a prevalência de suas deficiências e a possibilidade concreta do uso de suas determinações séricas como índices prognósticos em casos de cólica equina de origem gastrintestinal.

A partir dos resultados da presente pesquisa, é possível sugerir a presença relativamente comum e importante de hipocalcemia e hipomagnesemia em equinos com lesões gastrintestinais. Isto reforça a necessidade do constante acompanhamento dos valores séricos destas variáveis nos animais doentes, a fim de prover a adequada terapia de reposição visando à recuperação dos cavalos acometidos.

Palavras-chave: cálcio, magnésio, cólica, cavalos

\begin{abstract}
The prevalence of hypocalcemia and hypomagnesemia was evaluated in horses with gastrointestinal diseases. For that, 12 animals were examined at the UVV Veterinary Hospital. Age and gender of the animals, as well breed clinical diagnosis, adopted therapy and outcomes were recorded. Serum determinations of total calcium and magnesium were done on the day of admission and during the period of hospitalization. They revealed the presence of low levels of calcium and magnesium. The comparison between survivals and non-survivals on the admission day had shown a significant result only for serum calcium.
\end{abstract}

Keywords: calcium, magnesium, colic, horses 


\section{REFERÊNCIAS}

COSTA, L.R.R.; EADES, S.E.; TYULLEY, R.T. et al. Plasma magnesium concentrations in critically ill horses affected with gastrointestinal tract diseases. Adv. Magnesium Res.: Nutr. and Health, p.483-486, 2001.

DART, A.J.; SNYDER, J.R.; SPIER, S.J. et al. Ionized calcium concentration in horses with surgically managed gastrointestinal disease: 147 cases (1988-1990). J. Am. Vet. Med. Assoc., v.201, p.1244$1248,1992$.

DELESALLE, C.; DEWULF, J.; LEFEBVRE, R.A. et al. Use of plasma ionized calcium levels and $\mathrm{Ca}^{+}$ substitution response patterns as prognostic parameters for ileus and survival in colic horses. Vet. Q., v.27, p.157-172, 2005

GARCIA-LOPEZ, J.M.; PROVOST, P.J.; RUSH, J.E. et al. Prevalence and prognostic importance of hypomagnesemia and hypocalcemia in horses that have colic surgery. Am. J. Vet. Res., v.62, p.7-11, 2001 .

JOHANSSON, A.M.; GARDNER, S.Y.; JONES, S.L. et al. Hypomagnesaemia in hospitalized horses. J. Vet. Int. Med., v.17, p.860-867, 2003.

MANN, C.K.; YOE, J.H. Spectrophotometric determination of magnesium with I-azo-2-Hydroxy-3(2,4-dimethylcarboxanilido)-naphtalene-I'-(2-

hydroxybenzene). Anal. Chim. Acta, v.16, p.155-160, 1957.
MARTIN, L.G.; MATTESON, V.L.; WINGFIELD, W.E. Abnormalities of serum magnesium in critically ill dogs: incidence and implications. J. Vet. Emerg. Crit. Care, v.1, p.15-20, 1994.

NAVARRO, M.; MONREAL, L.; SEGURA, D. et al. A comparison of traditional and quantitative analysis of acid-base and electrolyte imbalances in horses with gastrointestinal disorders. J. Vet. Intern. Med., v.19, p.871-877, 2005.

ROSE, R.J.; HODGSON, D.R. Manual of Equine Practice. Philadelphia: Saunders, 2000. 818p.

SARKAR, B. C.; CHAUHAN, U.P. A new method for determining microquantities of calcium in biological material. Anal. Biochem., v.20, p.155-166, 1967.

STRUFALDI, B. Prática de Bioquímica Clínica. São Paulo: Faculdade de Ciências Farmacêuticas da Universidade de São Paulo, 1987. 399p.

ZALOGA, G.P.; WILKENS, R.; TOURVILLE, J. A simple method for determining physiologically active calcium and magnesium concentrations in critically ill patients. Crit. Care Med., v.15, p.813-816, 1987. 